\title{
Association of Lifestyle and Cardiovascular Risk Factors with Lung Function in a Sample of the Adult Italian Population: A Cross-Sectional Survey
}

\author{
Giovanna Laurendi $^{a} \quad$ Chiara Donfrancesco $^{b}$ Luigi Palmieri $^{b}$ Diego Vanuzzo ${ }^{c}$ \\ Giselda Scalera $^{a}$ Simona Giampaoli ${ }^{b}$ on behalf of the Osservatorio Epidemiologico \\ Cardiovascolare/Health Examination Survey 2008-2012 \\ a Department of Prevention, Ministry of Health, and ${ }^{\mathrm{b}}$ National Center of Epidemiology, Surveillance and Health Promotion, \\ National Institute of Health, Rome, and 'National Association Hospital Cardiologist (ANMCO), Foundation for Your Heart, \\ Florence, Italy
}

\section{Key Words}

Pulmonary function - Cardiovascular risk factors - Lifestyle

\begin{abstract}
Background: Some epidemiological studies have identified high values of pulmonary functions as an indicator of good health. At present little is known about the distribution of these characteristics in the general adult population. Objective: The aim of this study is to describe pulmonary function in the Italian general population and to evaluate its association with some lifestyle and cardiovascular risk conditions using data of the OEC/HES (Cardiovascular Epidemiology Observatory/Health Examination Survey) Project, a crosssectional survey based on the examination of random samples of the general population. Methods: A total of 9,108 men and women aged 35-79 years were examined between 2008 and 2012. Pulmonary function [forced expiratory volume in $1 \mathrm{~s}\left(\mathrm{FEV}_{1}\right)$ and forced vital capacity (FVC)] was measured with a spirometer and anthropometric measurements and blood pressure were also recorded, whereas lifestyle (physical activity, smoking habits), health status and drug treatment were assessed by a questionnaire. $\mathrm{FEV}_{1}$ and FVC $\%$ predicted were also calculated. Univariate analysis and a
\end{abstract}

multiple linear regression were performed in order to assess associations. Results: $\mathrm{FVC}$ and $\mathrm{FEV}_{1}$ percent predicted values were 98.0 (95\% Cl 97.4-98.6) and 107.3 (95\% Cl 106.6-107.9) for men and $108.7(95 \% \mathrm{Cl} 107.9-109.4)$ and $113.3(95 \% \mathrm{Cl}$ 112.6-114.1) for women. A lower mean FEV ${ }_{1}$ and FVC \% predicted value was found in smokers, individuals physically inactive during their leisure time, diabetics, obese individuals and hypertensive patients. Multivariate linear regression models confirmed the independent association between risk factors and FEV 1 and FVC levels. Conclusion: Our data confirm the inverse relationship existing between pulmonary function and cardiovascular risk factors, obesity, dyslipidemias and hypertension, all of which are conditions related to chronic diseases. An early public healthcare intervention on lifestyle could be useful to reduce the decline in pulmonary function.

(c) 2015 S. Karger AG, Basel

This work is part of the CUORE Project - Epidemiology and Prevention of Cardiovascular Disease, funded by the Italian Ministry of Health, coordinated by the National Center for Epidemiology, Surveillance and Health Promotion, Istituto Superiore di Sanita', Rome, Italy, and partly supported by the Center of Disease Control of the Ministry of Health.

\section{KARGER 125}

C 2015 S. Karger AG Base

0025-7931/15/0891-0033\$39.50/0

E-Mail karger@karger.com

www.karger.com/res
Giovanna Laurendi

Ministero della Salute

Direzione Generale Prevenzione, Ufficio IX

IT-00144 Rome (Italy)

E-Mail g.laurendi@ sanita.it 


\section{Introduction}

Pulmonary function is strongly related to physiological and pathological conditions [1]. Epidemiological studies have repeatedly demonstrated the inverse relationship existing among pulmonary function and chronic obstructive pulmonary disease (COPD) [2], lung cancer [3], cardiovascular disease [4] and diabetes [5]. Reduced pulmonary function has been reported to be inversely associated with cigarette smoking [6], obesity [7], metabolic syndrome [8] and conditions linked to an increased cardiovascular risk, such as high blood pressure, high cholesterol, a fast pulse rate and physical inactivity $[1,4]$.

Some studies have identified high values of pulmonary function as common indicators of health. Having a high vital capacity and being a nonsmoker are the main conditions that predict good health in the long term $[9,10]$.

Spirometry is the most frequently performed test to assess pulmonary function. The indicators that can be derived by spirometry include forced expiratory volume in $1 \mathrm{~s}\left(\mathrm{FEV}_{1}\right)$ and forced vital capacity (FVC). These indicators depend on height, weight, age and gender. Pulmonary function declines slowly throughout adult life, even in healthy individuals. This decline may accelerate after the age of 70 years [11]. Mean values of the European adult population are used to determine a normal range of results with expected predicted levels for $\mathrm{FEV}_{1}$ and FVC.

The purpose of this analysis was to describe the pulmonary function of the Italian adult population by FVC and $\mathrm{FEV}_{1}$ using data from a cross-sectional survey. A further objective was to assess the association of pulmonary function based on volume indices with some lifestyle and high-risk conditions for cardiovascular diseases.

\section{Methods}

We used data from the Cardiovascular Epidemiology Observatory/Health Examination Survey (OEC/HES; see Appendix), a cross-sectional survey conducted between 2008 and 2012 that aimed to describe individual lifestyles (nutrition, physical activity, smoking habit), cardiovascular risk factors (blood pressure, total and high-density lipoprotein (HDL) cholesterol, BMI, high fasting glucose), the prevalence of high-risk conditions (hypertension, dyslipidemia, obesity, diabetes) and cardiovascular diseases within a sample Italian population. A brief description of the survey methods is reported below; further information has already been published [12-14].

Twenty-three centers from all the Italian regions were selected, all having a common protocol. Training was provided to the technicians to guarantee a standardization of the collected data. Each center examined 220 out of every 1.5 million people of both sexes and within the age range of 35-79 years. This population sample was randomly selected from a list of residents, stratified by age and sex (25 people for each decade of age between 35 and 74 years, and an additional 10 people for the years 75-79). In total 9,107 people were examined, representing a participation rate of $55 \%$. For the purpose of this analysis the following risk factors and lifestyles were considered: height, weight, blood pressure, smoking habit, physical activity at work and during leisure time, total and HDL cholesterol, fasting blood glucose and ongoing treatments for hypertension, dyslipidemia, diabetes, COPD and asthma.

Height was measured in centimeters with a graduated rule fixed to the wall and readings were rounded to the nearest 0 or $5 \mathrm{~mm}$. Weight was measured with a balance beam scale; the measure was reported in kilograms and hectograms, and rounded to the nearest $200 \mathrm{~g}$.

Blood pressure was measured in the right arm with the subject in a sitting position using a Riva-Rocci mercury sphygmomanometer with 2 cuffs (normal and obese), and with a stethoscope bell for auscultation. Three consecutive measurements of blood pressure were recorded at intervals of a few minutes, and the mean of the three measurements was used in the analysis [14]. Fasting blood glucose and total and HDL cholesterol were measured in frozen serum using an enzymatic colorimetric method.

A standardized questionnaire was self-administered to collect personal and clinical information. The question concerning asthma or COPD was based on an awareness of suffering or having suffered from these conditions (with or without a documented diagnosis). Smoking habit was classified into two categories: nonsmoking, for those who have never smoked cigarettes or are former smokers, and current smoking, for smokers of one or more cigarette per day.

At work, physical inactivity was defined as generally being sat at a desk or not needing to walk. Inactivity in leisure was considered as time spent reading, watching television or doing other sedentary activities.

Subjects with systolic blood pressure $\geq 140 \mathrm{~mm} \mathrm{Hg}$ or diastolic blood pressure $\geq 90 \mathrm{~mm} \mathrm{Hg}$, or those under treatment were defined as hypertensive. Diabetes mellitus was defined as high fasting glucose levels $(\geq 126 \mathrm{mg} / \mathrm{dl})$ or being under treatment. Hypercholesterolemia was defined as a high blood cholesterol level $(\geq 240 \mathrm{mg} / \mathrm{dl}$ ) or being under treatment. Subjects considered to be overweight had a BMI between 25 and 30, whilst obesity was defined as BMI $\geq 30$.

Fatal and nonfatal 10-year cardiovascular risk functions of the CUORE Project were used to classify persons into two classes of risk ( $<20$ and $>20 \%)$. The individual risk score provides an assessment taking into account certain risk factors, such as age, gender, diabetes, smoking status, systolic blood pressure, and total and HDL cholesterol [15, 16].

Each participant of the study was well informed about the research purposes and was required to provide their signed informed consent before examination. The Ethics Committee of the Italian National Institute of Health approved the documentation related to the protocol of the study (informed consent, information notice for participants and curriculum vitae of the person responsible for the project), and approved all aspects of the study (March 11, 2008 and November 23, 2009).

\section{Spirometry}

SpiroPro, a small, portable spirometer that contains stored reference values based on age, sex, height and weight [17], was used. It was necessary to include each subject's full name, iden- 
tification number, sex, date of birth, height and weight, and explain to the person how they had to blow into the device (with as much force as possible into the mouthpiece after a deep inspiration with use of a nose clip). Two consecutive measurements were made, and the machine recorded the best one. FVC, the total volume of gas that can be exhaled after a full inspiration, and $\mathrm{FEV}_{1}$, the volume of exhaled air in the first second, both expressed in liters, were measured, as well as the ratio between the two values. The measurements of the person being tested were compared with their expected values with respect to the reference population of the same age, sex, weight and height. At the end of each day the results were printed out from the spirometer.

The recording program 'Envelope' was used to perform the flow-volume measurement. This program allows several breathing maneuvers to be performed during a test. When the test is completed, the program calculates the envelope from which the final values will be derived. This method leaves the machine with the best choice of spirometry recordings, which are then automatically saved. This method reduces the error associated with the operator in the subjective choice of spirometry results.

\section{Statistical Analyses}

Descriptive statistics based on classical cardiovascular risk factors and high-risk conditions were presented, reporting mean and standard deviation for continuous variables and prevalence rates for categorical variables by gender. The observed spirometry parameters $\left(\mathrm{FEV}_{1}, \mathrm{FVC}\right)$ were adjusted by dividing by height (in centimeters) and are reported as means and standard deviation according to gender and age class, as well as the percent of predicted values (observed parameter/predicted $\times 100$ ). The prevalence and $95 \%$ confidence intervals (CI) of pulmonary diseases (asthma and COPD) were estimated by gender and age class.

In order to singly assess the association between pulmonary function, lifestyle and high-risk conditions for cardiovascular diseases, the mean levels of $\mathrm{FEV}_{1}$ and $\mathrm{FVC}$ percent predicted value were tested among favorable and unfavorable habits/factors, with the following being considered unfavorable: smoking, overweight/obesity, physical inactivity, diabetes, hypertension, hypercholesterolemia and cardiovascular risk $\geq 20 \%$. Age-adjusted multivariate linear regression models were performed using $\mathrm{FEV}_{1}$ and FVC percent predicted as dependent variables, and lifestyle (smoking habit, physical inactivity during leisure time) and high-risk conditions (presence of asthma, COPD, obesity, diabetes, hypertension or hypercholesterolemia) as independent variables with the aim of evaluating their independent association to $\mathrm{FEV}_{1}$ and FVC. $\mathrm{R}^{2}$ was calculated for each model as an indicator of the degree of variance explained by the models. As a sensitivity analysis, univariate and multivariate analyses were replicated by age class (35-49 and 50-79) and the presence of pulmonary diseases.

The normality of the $\mathrm{FEV}_{1}$ and FVC distributions was tested graphically and using the Kolmogorov-Smirnov test. Both ANOVA (parametric) and Wilcoxon-Mann-Whitney (nonparametric) tests were performed to compare $\mathrm{FEV}_{1}$ and FVC distribution among lifestyle and high-risk conditions. A p value $\leq 0.05$ was considered statistically significant. Statistical analyses were performed using SAS software, release 9.2 (SAS Institute Inc., Cary, N.C., USA).

Cardiovascular Risk Factors and Lung Function

\section{Results}

We excluded men and women without observed and predicted $\mathrm{FVC}$ and $\mathrm{FEV}_{1}$, meaning that analyses were performed on a total of 3,845 men and 3,792 women. The mean BMI was within the overweight class, $22 \%$ of men and $19 \%$ of women were smokers, physical inactivity was reported by approximately one third of subjects, and hypertension and hypercholesterolemia were frequent conditions (table 1).

The prevalence of asthma and COPD did not significantly differ among men and women, and were measured as $10.2 \%(9.2-11.1 \%)$ and $9.7 \%(8.8-10.7 \%)$, respectively. By age class, the prevalence of asthma decreased and prevalence of COPD significantly increased (fig. 1).

Height-adjusted FVC and $\mathrm{FEV}_{1}$ were 23.1 (95\% CI 23.0-23.3) and 20.3 (95\% CI 20.1-20.4) for men, and 18.1 (95\% CI 17.9-18.2) and 15.9 (95\% CI 15.8-16.0) for women; $\mathrm{FVC}$ and $\mathrm{FEV}_{1}$ percent predicted were 98.0 (95\% CI 97.4-98.6) and 107.3 (95\% CI 106.6-107.9) for men and 108.7 (95\% CI 107.9-109.4) and 113.3 (95\% CI 112.6114.1) for women. Mean $\mathrm{FEV}_{1}$ and FVC levels significantly decreased by age class, both in men and women (table 2), and the $\mathrm{FEV}_{1}$ and FVC results displayed a normal graphical distribution.

$\mathrm{FVC}$ and $\mathrm{FEV}_{1}$ percent predicted were significantly lower in smokers, obese, diabetic and hypertensive persons, as well as in those who never do any kind of physical activity during their leisure time, both in men and women, with the exception of FVC in female smokers (tables 3, 4). FVC and $\mathrm{FEV}_{1}$ percent predicted were also significantly lower in hypercholesterolemic male subjects, as well as those at high cardiovascular risk. Smoking habit and the presence of obesity and diabetes are the most associated factors with FVC and $\mathrm{FEV}_{1}$, especially in men (difference columns, tables 3,4).

The significances of $\mathrm{FEV}_{1}$ and $\mathrm{FVC}$ comparisons among lifestyles and high-risk conditions were similar using ANOVA and the Wilcoxon-Mann-Whitney test. Multivariate linear regression models confirmed the independent association between favorable habits/factors and cardiovascular risk condition (nonobese, nonsmoker, nondiabetic, nonhypertensive and physically active) and levels of $\mathrm{FEV}_{1}$ and FVC, even if adjusted for the presence of pulmonary diseases (data not shown). In women, smoking seems not to be independently associated with FVC. $\mathrm{R}^{2}$ values raged from 0.018 in the female FVC model to 0.085 in the male $\mathrm{FEV}_{1}$ model. Similar associations among lifestyle, high-risk conditions and pulmonary functions were also shown between age classes and the presence of pulmonary diseases, albeit with a lower statistical power. 
Table 1. Risk factors and high-risk conditions for cardiovascular diseases in men and women aged 35-79 years

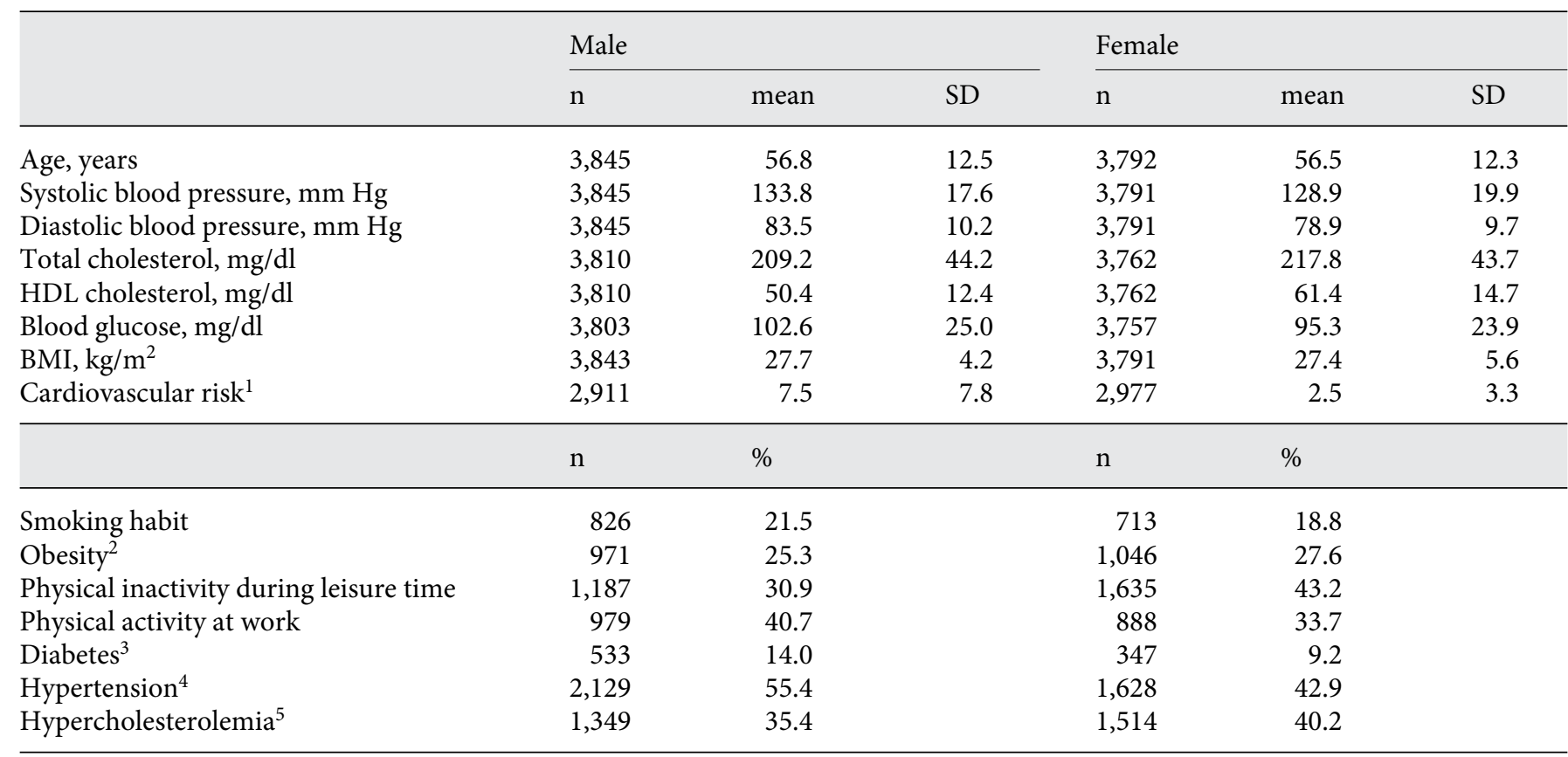

Data are from the OEC/HES Survey, 2008-2012.

${ }^{1}$ Risk score of the CUORE Project for the Italian risk assessment of 10-year fatal and nonfatal coronary and cerebrovascular diseases in primary prevention for persons aged 35-69 years, based on blood pressure, total and HDL cholesterol, diabetes and smoking habit.

${ }^{2}$ BMI $\geq 30$.

${ }^{3}$ Glycemia $\geq 126 \mathrm{mg} / \mathrm{dl}$, or under specific treatment.

${ }^{4}$ Systolic blood pressure $\geq 140$ or diastolic blood pressure $\geq 90 \mathrm{~mm} \mathrm{Hg}$, or under specific treatment.

5 Total cholesterol $\geq 240 \mathrm{mg} / \mathrm{dl}$, or under specific treatment.

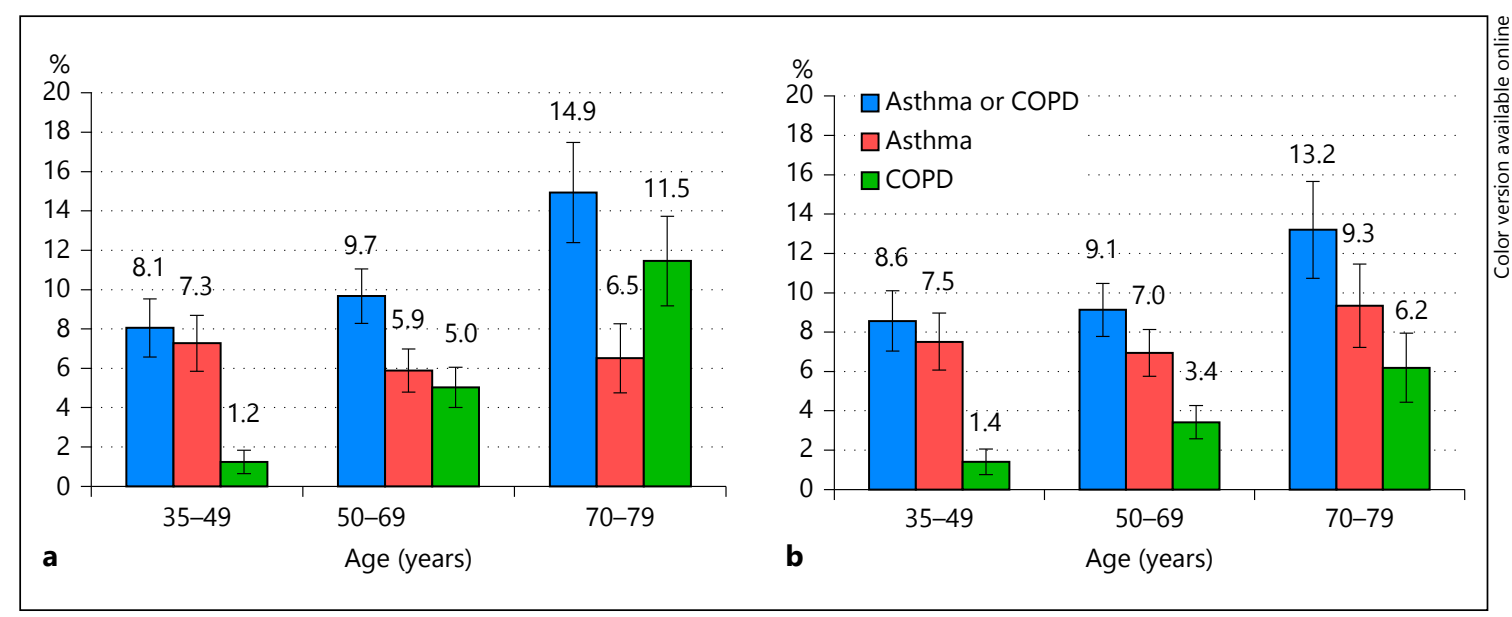

Fig. 1. Prevalence of asthma and COPD with $95 \% \mathrm{CI}$, presented by age class and gender: men (a) and women (b) aged 35-79 years. OEC/HES Survey, 2008-2012. 
Table 2. Distribution of FVC and $\mathrm{FEV}_{1}$ by age class and gender

\begin{tabular}{|c|c|c|c|c|c|c|c|c|c|c|c|c|c|}
\hline $\begin{array}{l}\text { Age class, } \\
\text { years }\end{array}$ & $\mathrm{n}$ & mean & $\mathrm{SD}$ & $\mathrm{p}$ value & mean & SD & $\mathrm{p}$ value & mean & SD & $\mathrm{p}$ value & mean & SD & $\mathrm{p}$ value \\
\hline $35-49$ & 1,298 & 26.9 & 4.7 & & 23.9 & 3.9 & & 102.2 & 17.8 & & 110.2 & 17.2 & \\
\hline $50-69$ & 1,785 & 22.5 & 4.8 & & 19.7 & 4.1 & & 98.4 & 20.4 & & 108.3 & 20.8 & \\
\hline $70-79$ & 762 & 18.2 & 4.5 & & 15.5 & 4.2 & & 89.9 & 21.9 & & 99.8 & 26.5 & \\
\hline \multicolumn{14}{|l|}{ Female } \\
\hline $35-49$ & 1,284 & 21.1 & 3.8 & & 18.8 & 3.0 & & 109.3 & 21.9 & & 113.3 & 18.0 & \\
\hline $50-69$ & 1,769 & 17.5 & 3.6 & & 15.4 & 3.1 & & 109.3 & 21.6 & & 114.3 & 22.2 & \\
\hline $70-79$ & 739 & 14.1 & 3.8 & & 12.0 & 3.2 & & 106.0 & 27.9 & & 111.1 & 29.2 & \\
\hline $35-79$ & 3,792 & 18.1 & 4.5 & $<0.0001$ & 15.9 & 3.9 & $<0.0001$ & 108.7 & 23.1 & 0.0020 & 113.3 & 22.5 & 0.0055 \\
\hline
\end{tabular}

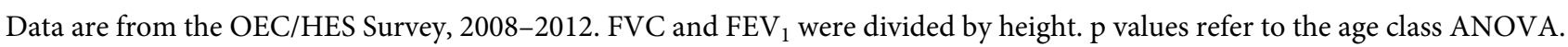

Table 3. Association of $\mathrm{FEV}_{1}$ percent predicted value and high-risk conditions for cardiovascular diseases in men and women aged 35-79 years

\begin{tabular}{|c|c|c|c|c|c|c|c|c|c|c|}
\hline & \multicolumn{10}{|c|}{$\mathrm{FEV}_{1}, \%$ predicted } \\
\hline & $\mathrm{n}$ & mean & SD & $\mathrm{p}$ value & difference ${ }^{1}$ & $\mathrm{n}$ & mean & $\mathrm{SD}$ & $\mathrm{p}$ value & difference ${ }^{1}$ \\
\hline Nonsmoker & 3,018 & 108.6 & 21.3 & & & 3,078 & 113.9 & 23.0 & & \\
\hline Current smoker & 826 & 102.2 & 20.9 & $<0.0001$ & -6.5 & 713 & 110.9 & 20.0 & 0.0004 & -3.0 \\
\hline Obese $^{3}$ & 971 & 102.7 & 22.3 & $<0.0001$ & -6.5 & 1,046 & 110.7 & 24.4 & $<0.0001$ & -2.8 \\
\hline Physical activity during leisure time & 2,652 & 108.8 & 21.3 & & & 2,152 & 114.2 & 21.8 & & \\
\hline Physical inactivity during leisure time & 1,187 & 103.9 & 21.2 & $<0.0001$ & -4.9 & 1635 & 112.2 & 23.3 & 0.0067 & -2.0 \\
\hline Physical activity at work & 1,427 & 108.5 & 19.6 & & & 1,747 & 113.3 & 20.1 & & \\
\hline Physical inactivity at work & 979 & 109.5 & 17.9 & 0.1895 & 1.0 & 888 & 113.2 & 20.8 & 0.9074 & -0.1 \\
\hline Nondiabetic & 3,269 & 108.4 & 20.5 & & & 3,411 & 113.8 & 22.3 & & \\
\hline Hypercholesterolemic $^{6}$ & 1,349 & 106.2 & 20.4 & 0.0166 & -1.7 & 1,514 & 114.0 & 23.7 & 0.1428 & 1.1 \\
\hline Cardiovascular risk ${ }^{7}<20.0 \%$ & 2,684 & 109.8 & 18.9 & & & 2,964 & 113.9 & 20.4 & & \\
\hline Cardiovascular risk ${ }^{7} \geq 20.0 \%$ & 227 & 106.0 & 19.7 & 0.0038 & -3.8 & 13 & 115.7 & 17.2 & 0.7571 & 1.8 \\
\hline
\end{tabular}

Data are from the OEC/HES Survey, 2008-2012. p values refer to ANOVA tests.

${ }^{1}$ Difference to $\mathrm{FVC}_{1}$ mean level of favorable and unfavorable risk conditions.

$225 \leq \mathrm{BMI}<30$.

${ }^{3} \mathrm{BMI} \geq 30$.

${ }^{4}$ Glycemia $\geq 126 \mathrm{mg} / \mathrm{dl}$, or under specific treatment.

${ }^{5}$ Systolic blood pressure $\geq 140$ or diastolic blood pressure $\geq 90 \mathrm{~mm} \mathrm{Hg}$, or under specific treatment.

${ }^{6}$ Total cholesterol $\geq 240 \mathrm{mg} / \mathrm{dl}$, or under specific treatment.

${ }^{7}$ Risk score of the CUORE project for the Italian risk assessment of 10-year fatal and nonfatal coronary and cerebrovascular diseases in primary prevention for patients aged 35-69 years, based on blood pressure, total and HDL cholesterol, diabetes and smoking habit.

Cardiovascular Risk Factors and Lung Function 
Table 4. Association of FVC percent predicted value and high-risk conditions for cardiovascular diseases in men and women aged 3579 years

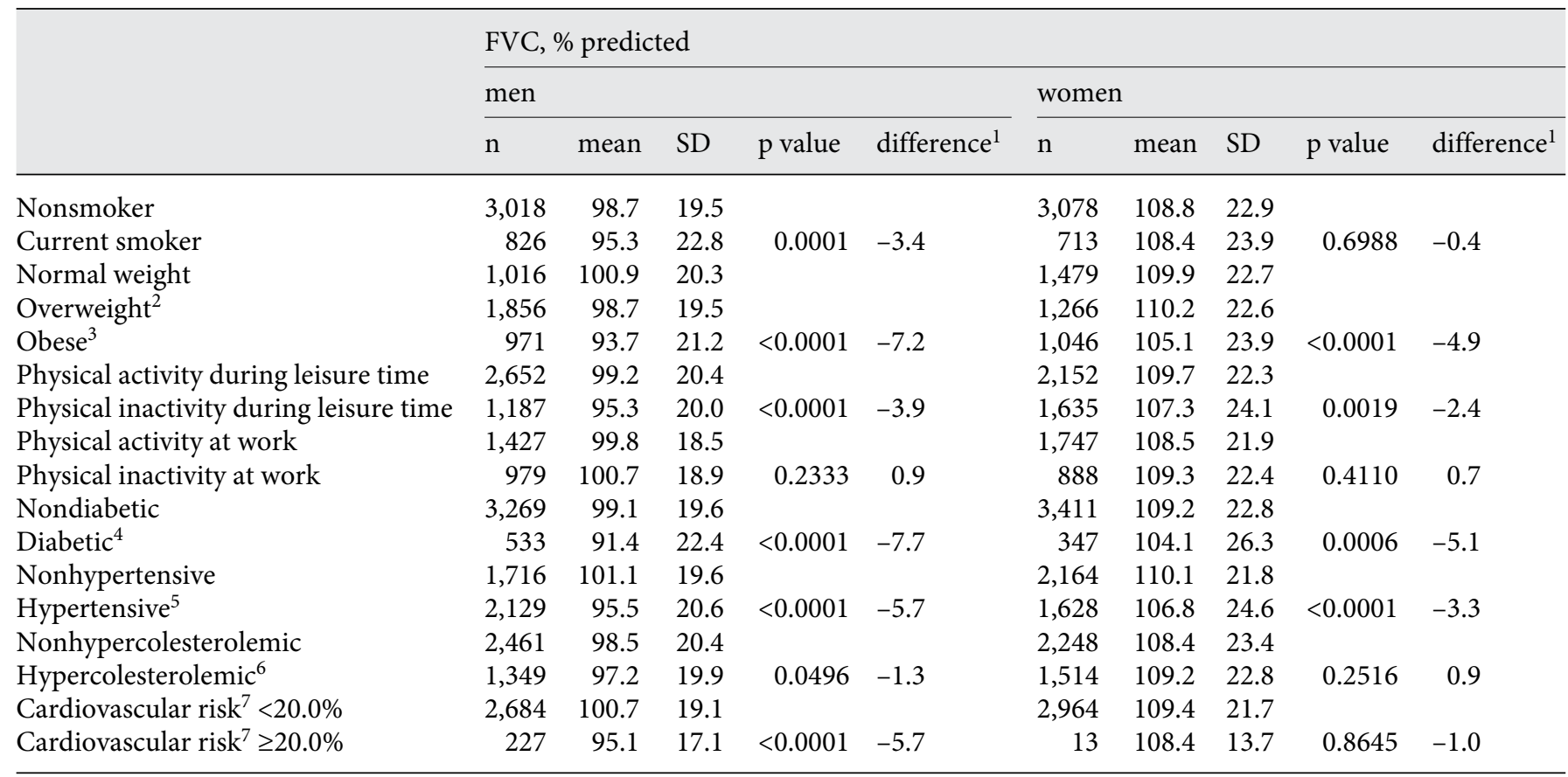

Data are from the OEC/HES Survey, 2008-2012. p values refer to ANOVA tests.

${ }^{1}$ Difference to FVC mean level of favorable and unfavorable risk conditions.

$25 \leq \mathrm{BMI}<30$.

${ }^{3} \mathrm{BMI} \geq 30$.

${ }^{4}$ Glycemia $\geq 126 \mathrm{mg} / \mathrm{dl}$, or under specific treatment.

${ }^{5} \mathrm{SBP} \geq 140$ or DBP $\geq 90 \mathrm{~mm} \mathrm{Hg}$, or under specific treatment.

${ }^{6}$ Total cholesterol $\geq 240 \mathrm{mg} / \mathrm{dl}$, or under specific treatment.

${ }^{7}$ Risk score of the CUORE project for the Italian risk assessment of 10-year fatal and nonfatal coronary and cerebrovascular diseases in primary prevention for patients aged 35-69 years, based on blood pressure, total and HDL cholesterol, diabetes and smoking habit.

\section{Discussion}

This study has provided the opportunity to describe pulmonary function in the Italian general adult population and to analyze the relationship between lifestyle, high cardiovascular risk conditions and pulmonary function. Results from the self-administered questionnaire show that the prevalence of COPD increases from the fist age class to the last in both men and women, whilst asthma seemed not to significantly change among age classes.

In recent years, some studies have evaluated the impact of different airway obstruction definitions on the estimated prevalence of obstruction in general population samples. Some screening programs have been performed in the population at risk, showing a large variability in COPD prevalence. The prevalence of COPD varied from
$4.9 \%$ ( $40-49$ years) to $12.3 \%$ (60-69 years) in males, and from $1.4 \%$ ( $40-49$ years) to $4.5 \%$ (60-69 years) in females [18].

To be nonobese, a nonsmoker, nondiabetic, nonhypertensive and nondyslipidemic is a condition positively related to pulmonary function in both genders. In other words, our data confirm that pulmonary function is inversely associated with unfavorable lifestyles and highrisk conditions for cardiovascular disease. To be physically active during work seems not to be related with pulmonary function.

To our knowledge there is a paucity of studies investigating the relation between pulmonary function, lifestyle and cardiovascular risk factors. However, the few studies confirm that reduced pulmonary function is associated with cardiovascular risk factors $[1,19]$. Multivariate models have also confirmed the independent association of 
cardiovascular lifestyles, high-risk conditions and lower levels of $\mathrm{FEV}_{1}$ and FVC.

Some methodological issues need to be discussed. Spirometry is the most frequently performed lung function test and is the most sensitive and specific test for detecting airflow limitation. Predicted values play an important role in establishing whether the volumes measured in an individual fall within a range to be expected in a healthy person of the same gender, height and age. Airway obstruction increases airway resistance, which can be measured using a body plethysmograph or a forced oscillator or interrupter. However, these instruments are much more expensive than spirometers, and the results (airway resistance, specific conductance of the airways and total respiratory resistance) are more variable than $\mathrm{FEV}_{1}$ and $\mathrm{FVC}$, resulting in a higher misclassification rate for airflow limitation $[6,20]$. Moreover, they are not applicable for screening of the general population.

The recording program used to perform the flow-volume measurement was 'Envelope', which enables the device to select and automatically save the best choice of spirometry readings (highest sum of $\mathrm{FEV}_{1}+\mathrm{FVC}$ ). This allows error to be reduced by eliminating the operator's subjective choice of spirometry results.

Some limitations of the study should be mentioned. First, this is a cross-sectional study; therefore, it does not allow investigation of the cause-effect relationship between cardiovascular risk factors and lung function measured by $\mathrm{FEV}_{1}$ and FVC. Prospective analyses of longitudinal data would allow for stronger conclusions to be made. Second, the prevalence of asthma and COPD was based on a self-reported questionnaire which could underestimate the real prevalence of diseases in the population; however, to our knowledge, no prevalence data based only on documented diagnoses exists at a national level. Therefore, the data reported here represent a rare opportunity to asses the burden of the main pulmonary diseases at the national level in Italy.

Some strengths of the study are also worth mentioning. First, the huge number of subjects enrolled in the study allowed the reliable assessment of mean levels of $\mathrm{FEV}_{1}$ and $\mathrm{FVC}$, and analysis of their relation with lifestyle and risk factors in the general adult population. Second, to obtain a complete and useful picture of the whole Italian territory, all Italian regions were included, corresponding proportionally with the resident population. Third, in order to avoid bias due to different numbers within certain age classes or between genders, the design of the study provided a stratified sampling procedure guaranteeing sufficient subjects in each age and gender class. Finally, lifestyle and risk factors were collected using standardized methods to allow comparison with other studies.

\section{Conclusion}

Our results showed an inverse relationship between respiratory function and smoking habit, presence of obesity and diabetes. These risk factors are related to cardiovascular diseases and chronic diseases in general. Contrary to common feeling, pulmonary function depends not only on smoking habit, but also on other lifestyle characteristics and high-risk factors for cardiovascular disease. An early public healthcare lifestyle intervention could be useful to reduce cardiovascular risk factors and the decline in pulmonary function.

\section{Appendix: Research Groups of the OEC/HES}

\section{Directors}

S. Giampaoli: Istituto Superiore di Sanità, Roma.

D. Vanuzzo: Associazione Nazionale Medici Cardiologi Ospedalieri, Area Prevenzione, Firenze.

S. Giampaoli, L. Palmieri, C. Lo Noce, F. Dima, C. Donfrancesco, S. Vannucchi: Istituto Superiore di Sanità, Roma.

D. Vanuzzo, A. Boccanelli, F. Bovenzi, F. Chiarella, F. Colivicchi, G. Di Pasquale, P. Faggiano, A.P. Maggioni, G. Mureddu, S. Pede, S. Pirelli, C. Riccio, M. Scherillo, S. Urbinati, M. Uguccioni, P. Verdecchia, M.M. Gulizia: Associazione Nazionale Medici Cardiologi Ospedalieri, Fondazione per il tuo Cuore, Firenze.

\section{Centers}

D. Vanuzzo, L. Pilotto, G. Brianti, R. Mirolo, F. Picco, A. Colò, F. Mattiussi, G. Picco, I. Russo, L. Fusco, A. Minigutti, M. Martini, S. Gigante, E. Zanin: Centro di Prevenzione Cardiovascolare ASS 4 'Medio Friuli', Udine.

L. Iacoviello, F. Gianfagna, M.R. Persichillo, A. De Curtis: Centro di Ricerca e Formazione ad Alta Tecnologia nelle Scienze Biomediche Giovanni Paolo II, Università Cattolica, Campobasso.

F. Vancheri, A.M. Giuffrida, M. Alletto, C. Asaro, S. Bartolotta, R. Dovico, A.M. Baldini, G. Cicardo, A. Cigna, R. Di Vara, G. Gallo, L. Gibbarrasi, I.G. Infantino, A. Meloni, P. Mirisola, A. Patrì: Ospedale S. Elia, Caltanissetta.

C.A. Goldoni, G. De Girolamo, G. Carrozzi, C. Rossi, G. Gatti, K. Bonora, A. Schiavi, G. Siena, L. Bolognesi, L. Sampaolo, R. Anderlini, L. Grassi, A. Pavarelli, V. Bevini, D. Lelli: Dipartimento di Sanità Pubblica Azienda USL, Modena.

C.A. Caserta, G.M. Pendino, A. Messineo, A. Foci, A. Alessi, A. Calarco, G. Cuzzola, G. Gutamo, M. Marra, D. Sergi: Associazione Calabrese di Epatologia, Cittanova.

A. Lopizzo, M. Nolè, I. Bochicchio, L. Coviello: Ospedale S. Carlo, Potenza. 
N. Meloni, G. Serra, O. Casula, O. Casula, V. Lai, S. Leone, A.F. Murgia, R. Serra: USL 4 Loceri, Nuoro.

M. Gattone, P. Giannuzzi, P. Sacco, L. Perini, B. Temporelli, I. Van den Berg, C. Ferrari, G. Omarini, E. Guglielmetti, I. Gnemmi, N. De Stefano, M. Colombo: Fondazione S. Maugeri, Veruno.

G. Salamina, G. Modolo, F. Cavalero, R. Clari, V. Stefanini, R. Boero, C. Zaranella, R. Fenoil: SC Centro Controllo Malattia, ASL TO1, Torino.

A. Boccanelli, V. Rizziello, M. Panei, G. Buonsanto, S. Bonanni, E. Cambiotti, R. Colasanti, S. Colavita, V. Coppola, F. D’Agostino, T. D’Allestro, D. Di Marco, A. Ferrara, C. Fortunato, M. Gigliofiorito, F. Lagioia, M.A. Maceroni, P. Moreddu, A. Nappini, G. Pallocca, M. Palombo, V. Spoletini, L. Vana, V.L. Viggiani, M. Vitale, A. Vivona, M. Zelli: Ospedale S. Giovanni Addolorata, Roma.

R. Amici, R. Greco, N. Di Nardo Di Maio, M. Bracalenti, S. Pierfaustini: Ospedale Santa Maria della Pietà, Camerino.

G. Alunni, C. Zuchi, A. Biadetti, A. Mengoni, C. Tutarini, G. Guglielmini: Ospedale S.M. della Misericordia, Azienda Ospedaliera di Perugia.

G. Favretto, S. Matteazzi, R. Pizzin, G. Borin, M. Marson, D. Maloco, P. Vivan, G. Scapolan, G. Stefanato, L. Frassetto, D. Borgolotto: Ospedale Riabilitativo di Alta Specializzazione, Motta di Livenza.
M. Vettori, D. Noventa, D. Froni, S. Carraro, R. Riccato, S. Guaita: Azienda USL 13 del Veneto, Noale.

M. Scherillo, D. Raucci, P. Silvestri, V. Procaccini, M. De Vizia, A. Patierno, R. Donatiello: Azienda Ospedaliera G. Rummo, Benevento.

P. Faggiano, G. Faden, E. Locantore, O. Cinelli, V. Ghini, M. Arcena, S. Vitali, G. Belleri, P. Di Domenico, V. Lauria, L. Papa, S. Pezzetta, D. Bino, D. Lonati: Azienda Ospedaliera Spedali Civili, Brescia.

M.T. La Rovere, S. Colombi, R. Ghelfi, A. Bianchini, L. Castagna, A. Di Bari, F. Lenta, E. Bellinzona, E. Zambianchi, S. Bianco, D. Gargulli, N. Mancin, E. Moretti, A. Nicolini, M. Panetti, A. Tosi: Fondazione Salvatore Maugeri, Istituto di Riabilitazione di Montescano.

M.L. Biorci, R. Griffo, R. Debenedetti, R. Bettaglio, F. Villani, A. Morando, C. Tardivelli: ASL 3 Genovese-PO 'La Colletta', Arenzano.

P. Caldarola, G. Bulzis, A. Dachille, I. Dentamaro, R. Riccardi, C. Caterina, A. Basile, A. Pasculli, M. Tarantino, F. Scaraggi, V. Spadone, P. Di Terlizzi, A. Sivo, A. Mongello, S. Pazienza, D. Natale, P. De Palo, C. Zucaro, N.A.G. Liso, C. Di Cagno, N. Spadavecchia, M. Sassara, P. Carelli: Cardiologia dell'Ospedale di Terlizzi, Bitonto, Bari.

\section{References}

1 Arcari A, Magnacca S, Bracone F, Costanzo S, Persichillo M, Di Castelnuovo A, de Curtis A, Zito F, Schünemann HJ, et al: Relation between pulmonary function and 10-year risk for cardiovascular disease among healthy men and women in Italy: the Molisani Project. Eur J Prev Cardiol 2013;20: 862-871.

-2 Akkermans RP, Berrevoets MA, Smeele IJ, Lucas AE, Thoonen BP, Grootens-Stekelenburg JG, Heijdra YF, van Weel C, Schermer TR: Lung function decline in relation to diagnostic criteria for airflow obstruction in respiratory symptomatic subjects. BMC Pulm Med 2012;12:12.

$>3$ Fry JS, Hamling JS, Lee PN: Systematic review with meta-analysis of the epidemiological evidence relating $\mathrm{FEV}_{1}$ decline to lung cancer risk. BMC Cancer 2012;12:498.

4 Keys A, Aravanis C, Blackburn, et al: Seven Countries: A Multivariate Analysis of Death and Coronary Heart Disease. Cambridge, Harvard University Press, 1980.

$>5$ Walter RE, Beiser A, Givelber RJ, O’Connor GT, Gottlieb DJ: Association between glycemic state and lung function: the Framingham Heart Study. Am J Respir Crit Care Med 2003; 167:911-916.

6 Higgins MW, Enright PL, Kronmal RA, Schenker MB, Anton-Culver H, Lyles M: Smoking and lung function in elderly men and women: the cardiovascular health study. JAMA 1993;269:2741-2748.

7 Bottai M, Pistelli F, Di Pede F, Carrozzi L, Baldacci S, Matteelli G, Scognamiglio A, Viegi G: Longitudinal changes of body mass index, spirometry and diffusion in a general population. Eur Respir J 2002:20:665-673.

8 D’Avila Melo SM, Melo VA, Menezes Filho RS, Santos FA: Effects of progressive increase in body weight on lung function in six groups of body mass index (in Portuguese). Rev Assoc Med Bras 2011;57:509-515.

-9 Songür N, Aydin ZD, Oztürk O, Sahin U, Khayri U, Bircan A, Akkaya A: Respiratory symptoms, pulmonary function, and reproductive history: Isparta Menopause and Health Study. J Womens Health 2010;19: 1145-1154.

10 Menotti A, Conti S, Farchi G, Giampaoli S, Dima F, Seccareccia F, Giuli B, Torsello S, Morisi G, Buongiorno A: The prediction of future health in healthy middle-aged men. Eur J Epidemiol 1986;2:233-239.

$>11$ Lazarus R, Gore CJ, Booth M, Owen N: Effects of body composition and fat distribution on ventilatory function in adults. Am J Clin Nutr 1998;68:35-41.

12 Giampaoli S, Vanuzzo D, Palmieri L, Lo Noce C, Dima F, De Sanctis Caiola P, Donfrancesco C, Ciccarelli P, Toccaceli V: Progetto CUORE. Epidemiologia e prevenzione delle malattie cardio-cerebrovascolari. Protocollo e manuale delle operazioni dell'Osservatorio Epidemiologico Cardiovascolare/Health Examination Survey 2008-2011. Rapporti Istisan 2010; 10:80.

13 Giampaoli S, Vanuzzo D, Research Group of the OEC/HES: La salute cardiovascolare degli italiani. Terzo Atlante Italiano delle Malattie Cardiovascolari - Edizione 2014. G Ital Cardiol 2014;15(suppl 1):7S-31S.
14 Lazarus R, Gore CJ, Booth M, Owen N: Effects of body composition and fat distribution on ventilatory function in adults. Am J Clin Nutr 1998;68:35-41.

15 Palmieri L, Rielli R, Demattè L, Donfrancesco C, Ciccarelli P, De Sanctis Caiola P, Dima F, Lo Noce C, Brignoli O, et al: CUORE project: implementation of the 10-year risk score. Eur J Cardiovasc Prev Rehabil 2011;18:642649

16 Giampaoli S, Palmieri L, Donfrancesco C, Panico S, Vanuzzo D, Pillotto L, Ferrario M, Cesana G, Mattiello A: Cardiovascular risk assessment in Italy: the CUORE Project risk score and risk chart. Ital J Public Health 2007; 5:102-109.

17 Peslin R, Bohadana A, Hannhart B, Jardin P: Comparison of various methods for reading maximal expiratory flow-volume curves. Am Rev Respir Dis 1979;119:271-277.

18 Maio S, Sherrill DL, MacNee W, Lange P, Costabel U, Dahle SE, Sybrecht GW, Burghuber OC, Stevenson R, et al: The European Respiratory Society spirometry tent: a unique form of screening for airway obstruction. Eur Respir J 2012;39:1458-1467.

19 Onishi K, Yoshimoto D, Hagan GW, Jones PW: Prevalence of airflow limitation in outpatients with cardiovascular diseases in Japan. Int J Chron Obstruct Pulmon Dis 2014;9:563568.

20 Ostrowski S, Grzywa-Celińska A, Mieczkowska J, Rychlik M, Lachowska-Kotowska P, Lopatyński J: Pulmonary function between 40 and 80 years of age. J Physiol Pharmacol 2005: 56(suppl 4):127-133. 